This is an author produced version of a paper published in British food journal.

This paper has been peer-reviewed and is proof-corrected, but does not include the journal pagination.

Citation for the published paper:

Nilsson, J., Lind, LW. (2015) Institutional changes in the Swedish meat industry. British food journal. Volume: 117, Number: 10, pp 2501-2514. http://dx.doi.org/10.1108/BFJ-11-2014-0378.

Access to the published version may require journal subscription. Published with permission from: Emerald.

Epsilon Open Archive http://epsilon.slu.se 


\title{
Institutional changes in the Swedish meat industry ${ }^{1}$
}

\begin{abstract}
Purpose - To explain institutional changes in the Swedish meat industry after major external events.
\end{abstract}

Design/methodology/approach - Analyses based on secondary data sources and interviews with people involved when the dominant meat co-operative in Sweden underwent major changes.

Findings - The decline in the Swedish meat industry is interpreted using the theory of institutional change presented by Aoki (2007; 2011). The country's former national agricultural policy created a specific set of norms and values. Co-operatives were considered to be indispensable. The co-operative sector was large and hierarchically organised. Therefore, external signals did not create sufficient endogenous processes within the cooperatives. Co-operative adaptation to rising competitive pressure took place only reluctantly and belatedly. Hence many farmer-members defected and the major co-operative faced finally unsurmountable problems. A strong ideological conviction caused the once dominant co-operative to collapse and much of the Swedish meat industry to disappear.

Originality/value - This study shows that strong ideology (here a conviction about the advantages of politically governed co-operatives) can hamper endogenous processes within an organisation. Management may ignore outside influences, to the extent that even a large industry is impaired. Other large, hierarchically structured and top-governed organisations with a strong ideology may behave in a similar way.

Keywords Institutional change, slaughterhouse, co-operative, conversion, Sweden, agricultural policy

Paper type Research paper

\footnotetext{
${ }^{1}$ Nilsson, J. and L.W. Lind. Institutional changes in the Swedish meat industry. British Food Journal, 117 (10), pp. $2501-2514$.
} 


\section{Introduction}

In 1999, four regional meat co-operatives in Sweden had operational problems, so they took the first step towards merging into an almost nationwide co-operative, which had an aggregate market share of $60-80 \%$ of the market for slaughtered animals. The full merger took place in 2001. In spite of its market dominance, the co-operative's financial performance kept on weakening. In 2007 it was acquired by a multinational meat processing firm, since the farmer-members considered it impossible to rescue the business. By then much of the once strong meat sector had already disappeared.

This study aims at explaining these institutional changes in Sweden's meat industry. It is claimed that the demise of the co-operative sector can be understood in terms of endogenous processes, spurred by some political (exogenous) changes (Aoki, 2007; 2011).

Many previous studies have investigated co-operatives that have run into difficulties, using a variety of theoretical bases such as cultural theory (Hogeland, 2006), population ecology (Bager, 1996), social capital theory (Nilsson, Svendsen and Svendsen, 2012), the notion of "vaguely defined property rights" (Cook, 1995), transaction cost theory (Harte, 1997), management theory (Hind, 1999), the notion of free-riding (Nilsson and Svendsen, 2011), social psychology (Nilsson, Kihlén and Norell, 2009) and sociology (Ilmonen, 1992). The present study is the first to use the theory of institutional change to explain why a cooperative collapsed - and thereby caused a decline in an important industry.

Section 2 of this paper presents the external factors that created problems for the meat cooperatives studied here. One such factor is that Sweden's longstanding agricultural policy was dismantled in 1990. Another is that in 1995, Sweden joined the European Union (EU) and cheap imported products became highly demanded by consumers. The meat co-operative sector in particular was deeply affected by the low-price competition.

Following that background, Section 3 provides an account of the theory of institutional change, which is used here to interpret the developments in the Swedish meat industry. Section 4 presents the methodological deliberations in connection with collecting and analysing empirical data and the data are analysed in terms of the theory of institutional change in Section 5. Finally, in Section 6 conclusions are drawn from the results.

\section{Background}

\subsection{The national agricultural policy}

In 1990 Sweden dismantled its national agricultural policy, which was first introduced in the 1930s following an economic crisis. It was expanded during World War II and the difficult years thereafter. This policy became increasingly all-encompassing over the next decades. An important instrument for realising the policy was the existence of farmers' co-operatives. Government subsidies to agriculture were allocated through farmers' organisations, first a federal agricultural organisation and then a co-operative society. The amount of subsidy funding was decided after bargaining between the farmers' federation and a specific government body. 
The agricultural policy aimed at providing "self-sufficiency for defence reasons ... environmental protection ... a fair income goal ... the protection of backward areas and the production of 'high quality' food" (Rabinowicz et al., 1986, p. 325). These objectives were achieved through varied import levies to raise domestic prices, mandatory domestic market intervention implemented by semi-public marketing associations and export subsidies, funded by variable production levies (Rabinowicz, 2004, p. 2).

Swedish farmers" organisations had an "almost complete monopoly" (Rabinowicz et al., 1986, p. 323). The intention was that if the co-operatives could achieve a large market share, "the price support would not be captured by the middle-men even if the price-regulating measures were implemented beyond the farm gate at later stages of the marketing channel" (ibid., pp. 326-327).

All co-operatives and all farmers were dependent upon the farmers' federation's price negotiations, so a strict hierarchal pattern existed. Farmers had strong incentives to become members of a co-operative (Micheletti, 1987). Only a few farmers had such strong anti-cooperative convictions that they patronised the small number of weak investor-owned firms (IOF), thereby simultaneously resisting social pressure from their fellow farmers (Pestoff, 1991) and the widespread co-operative ideological values about solidarity, fairness and equality (Nilsson, 1997). However, those farmers still received good prices thanks to the government policy (Rabinowicz et al., 1986, p. 327)

The political support made it possible for the co-operatives to become very wealthy, because "... the protection system now favours the processing industry rather than the farmers". (Rabinowicz et al., 1986, p. 331)

According to the competition policy of those days, the co-operatives were not permitted to compete with each other. They were allotted geographical borders, outside which they were not allowed to buy agricultural products or market their processed products. The cooperatives used the traditional co-operative principle of delivery obligations, i.e. their members were obliged to deliver all their products to the co-operative. Product volumes which the co-operatives could not sell within their region were sold to co-operative federations within each of the agricultural industries. Most of these organisations had sizeable processing activities. Volumes that could not be sold on the domestic market were offloaded on the world market.

In 1990, the Swedish Parliament decided unanimously that the country's agricultural policy would be abolished. The support for agriculture was considered a heavy burden on the national economy.

\subsection{Sweden's accession to the EU}

The abolition of the policy was intended to take place over a five-year period. However, only limited liberalisation measures were introduced. There was a widespread opinion that swift deregulation was not necessary, since Sweden was expected soon to become an EU member country, whereupon the Common Agricultural Policy (CAP) would be implemented in Sweden (Rabinowicz, 2004). Accession to the EU took place in 1995. 
After Sweden's entry into the EU, imported food products acquired a large share of the market, as consumers were more attracted to the low prices than to domestic origin. Swedish food processors were forced to reduce their selling prices, but they could not pass on these reductions in prices to farmers, because few farms would have survived in that case.

The Swedish meat industry declined continuously following EU accession. The total number of pigs decreased by 40\% between 1995 and 2013, while the number of pig breeders fell by 80\% between 2000 and 2013 (Swedish Board of Agriculture, 2013). The number of pigs sent to slaughter fell from 1,239,000 in 1999 to 847,000 in 2013. Nevertheless, consumption of meat steadily increased, with the increased demand being met by imported products. For example, the per capita consumption of pig meat rose by 5\% between 2000 and 2010 (Swedish Board of Agriculture, 2014).

\subsection{The meat co-operatives ${ }^{2}$}

There have been many local and regional meat co-operatives in Sweden since the first one was established in 1899. After many mergers had taken place, in the early 1990s there were five regional co-operatives, which together accounted for 70-90\% of all the animals slaughtered (pigs, cattle and sheep). The meat co-operative sector also comprised a national federation, which owned several processing plants. The co-operatives dominated not only the market for slaughter animals but also later stages in the value chain, although with successively lower market share, for example about $30 \%$ of meat products sold to end consumers.

Once Sweden had joined the EU, the co-operatives' business operations faced great economic problems (Nilsson, 1997). The managers of the regional co-operatives decided that a merger would be a solution. The negotiations failed, however, so in 1999 four of the five cooperatives agreed to establish a collaborative arrangement, called Swedish Meats (Swedish Meats, 1999). It was hoped that the cultures in the merging partners would be aligned to pave the way for a future full merger.

Renewed negotiations resulted in a merger decision in 2001. However, merging into one primary co-operative did not result in better performance. For example, even though four of the previous seven processing plants were closed, Swedish Meats still had excess capacity. Half the aggregate equity capital the co-operatives possessed in 1995 was lost by 2003.

Due to unremitting losses, Swedish Meats ultimately had to lower the prices paid to its members. Hence, the membership fell from about 33,000 in 2002 to 22,000 in 2006. As the exiting members were mainly large-scale farmers, the allocated equity capital of Swedish Meats fell by $50 \%$ in the same period. The number of animals sent to slaughter also declined. For example, in 2000 Swedish Meats accounted for $77 \%$ of the country's slaughter pigs, but by the end of 2006 its market share was $63 \%$.

In the first three years after the merger, Swedish Meats made large annual losses (see Table I). For example, in 2002 the loss corresponded to $14 \%$ of the equity capital. In later years there were some improvements, possibly as a result of closure of redundant production

\footnotetext{
2 This section is based on secondary material, especially annual reports from Swedish Meats (1999-2007), Nilsson and Björklund (2003), Andersson and Thorstensson (2010), Lind (2011), Hess et al. (2013) and mass media.
} 
plants, but possibly also due to the Board of Directors realising that the enterprise had to be sold and therefore no investments were made, thereby creating an advantage in negotiations with prospective buyers.

In 2007, a majority of the delegates at Swedish Meats' General Assembly decided to sell the business. The buyer was a profit-maximising meat processing firm with operations in most countries around the Baltic Sea. This firm is listed on the Helsinki Stock Exchange, but most of the directors are from a society of Finnish animal producers.

During the years when the co-operatives had economic problems, there were also a small number of IOF slaughterhouses, mainly family-owned businesses, in Sweden. These businesses expanded their volumes in connection with EU accession. They were most often profitable even though they paid higher prices to farmers than Swedish Meats. In some regions where Swedish Meats had closed production plants, farmers established new abattoirs (Hakelius et al., 2013). The regional meat co-operative that did not join the four others in the merger was sold a few years later to a Danish meat processing firm.

Table I. Selected financial figures from the five full years when Swedish Meats was operating

\begin{tabular}{lrrrrr}
\hline & $\mathbf{2 0 0 2}$ & $\mathbf{2 0 0 3}$ & $\mathbf{2 0 0 4}$ & $\mathbf{2 0 0 5}$ & $\mathbf{2 0 0 6}$ \\
\hline Net sales, million SEK & 9,157 & 8,648 & 8,287 & 8,872 & 10,038 \\
$\begin{array}{l}\text { Profit/loss after interests and tax, } \\
\text { millions of SEK }\end{array}$ & 124 & -154 & 63 & 33 & 62 \\
$\quad$ & & & & & \\
Operating profit/loss (comparable & -5 & -128 & -5 & 2 & -47 \\
$\quad$ units), millions of SEK & & & & & -208 \\
Cash flow, millions of SEK & 406 & -105 & 94 & -7 & 27 \\
$\quad$ Equity ratio, \% & 32 & 30 & 30 & 31 & 20 June \\
(Source: Swedish Meats' Annual Report, 2006. SEK 100 = EUR 9.25, USD 8.12 and GBP 12.84 on 22 \\
2015)
\end{tabular}

\section{The theory of institutional change}

The changes within the Swedish meat industry described above, especially those in the cooperative business sphere, can be understood with the help of the theory of institutional change. Using North (1990) as his point of departure, Aoki $(2007$, p. 6) suggests that institutions are "self-sustaining, salient patterns of social interactions, as represented by meaningful rules that every agent knows and are incorporated as agents' shared beliefs about how the game is played and to be played." Institutions thus constitute sets of rules and norms, conceptions and ideas, all of which direct the behaviour of individuals, groups and organisations. Because the rules and norms evolve sequentially, the concept of 'path dependence' has become a hallmark in the literature on institutional change.

Aoki (2011) provides "a unified framework for incorporating various views of institutions" (ibid., p. 21). Institutional changes occur constantly within all social settings, be it industries (the Swedish agricultural sector at large), organisations (co-operatives, other meat processing firms, retailers or farmer organisations) or networks (the farmer community, consumers or the general public). Institutional changes are partly triggered by events that are external to the social system. In the case of the co-operative demise studied here, the exogenous influences were above all political changes. Other external factors may be consumers' shifting demand, intensified competition, product and organisational innovation, and criticism by researchers and mass media. 
All actors within the meat industry had to respond to these external factors, but the various categories of actors responded differently, thus changing the conditions for other actors to react. Hence institutional changes take place endogenously, i.e. through forces within various parts of the social system itself. These units interact simultaneously and reciprocally, so there are influences between them. According to Aoki (2007), changes occur within various domains ("proto-institutions"):

- The economic exchange domain may comprise the values and norms within the cooperatives under study here, the investor-owned competing slaughterhouses, and the various firms in the value chain, including the primary producers.

- The organisational exchange domain involves a variety of organisations such as the co-operative enterprise studied here with its board, management and staff, the cooperative society and various organisational levels within that hierarchy, the federal co-operative organisations, other food processing firms and retailers in the value chain, etc.

- The political exchange domain comprises politicians in various organisational contexts and their voters, but also the farmers' lobbying organisations. The leaders of the co-operatives, especially before the crisis, belong to the political sphere.

- The social exchange domain contains the animal-rearing farmers - both members of the co-operative and those delivering to investor-owned slaughterhouses. The general public is interested in agriculture, taxes, food product origin and many other topics.

When actors within one domain change their rules and norms and thereby their behaviour, actors in another domain will face a different reality. Therefore they in turn change their minds and their actions, causing yet others to change, and so on. Each actor may act in a way that is expected to serve their own interests, but due to the interplay with other actors who act in a similar way, everybody's interests may change over time.

Institutional changes are often associated with tensions within and between the domains, such as within and between units, for example politicians of different persuasions, management and the members of farmer organisation or producers at different stages of a value chain. These tensions urge actors to consider their opinions and their interaction with other actors. Changes outside the social system may give rise to external influences, which stimulate endogenously induced changes to become stronger.

Institutional changes may be viewed in terms of games, played by a variety of players and categories of actors with relationships to a social system. The strategic interactions of agents and their individual beliefs in societal games have implications for the role of culture, institutional complementarities and policies. The players have their own set of conceptions, beliefs, opinions, etc. - in short, culture - and each player has different information and different interests and capabilities. The players' actions are based on beliefs about how other players will behave. Hence actors change their norms and rules after having tried to anticipate the changes in other actors' norms and rules, and these other actors in turn change in response to what is happening with yet other actors. When "the rules of the political exchange game start to be modified, that would ... have feedback impacts on the corporate organization field in one way or another" (Aoki, 2011, p. 28). 
The actors involved in restructuring the Swedish meat industry were politicians, the cooperatives' governing bodies (Board of Directors and other elected representatives, as well as the top management), the IOF slaughterhouses, the animal-producing farmers and different categories of these (co-operative members and IOF suppliers), academics, the general public and the mass media. Some of these players acted in ways that changed the conceptions of others. These players had the possibility of acting in two or more of the four domains, which meant that they had ample chances to reciprocally influence each other, thus creating snowball effects.

Institutional change occurs in the competition between various norms, rules, ideologies, ideas and other conceptions that contribute to directing people's actions and interactions. These conceptions are represented by various individuals and groups of individuals, each consciously or unconsciously influencing others. New conceptions are born as existing conceptions are mixed or integrated into others. All conceptions are borne by individuals, acting on their own or within various social and organisational contexts. Individuals have various conceptions because these are expected to benefit them.

\section{Methodological approaches}

The present study is based on both secondary and primary sources. Facts about the Swedish agricultural policy, the country's accession to the EU and the development of the meat industry originate from secondary sources.

The amount of secondary data about co-operative development during the crisis years is limited by the fact that the directors gave little and skewed information to the mass media, including the agricultural media. Moreover, as Swedish Meats was a co-operative, there was little interest from financial analysts and business news media.

It was not possible to obtain direct information through a survey of members of Swedish Meats, since after the co-operative was sold no list of names and addresses of former members survived. Instead, primary data were obtained from individuals involved in Swedish Meats in the period when the co-operative was undergoing crisis. Thus individuals involved in attempts to rescue the co-operative and then to sell it were interviewed here. Interviews are the best data collection tool when individual historical accounts about a change are sought (King, 1994).

The interviewees within the former co-operative include directors who had taken an active part in the decision to sell the co-operative and other members. Of special interest were those who had publicly expressed an opinion for or against the sell-off. All the people targeted for interviews had been members of the co-operative. However, most of the directors who acted for the demutualisation declined to participate.

At the end of May 2009, semi-structured interviews were conducted. The plan was to interview a large number of people, but as one respondent after another gave very similar answers, only six interviews were held. The interviewees had received in advance a list of questions, which covered issues such as the deliberations concerning the institutional changes. The questions were of an open-ended nature in order to enhance the flexibility, stimulate in-depth answers and allow the interviewee to produce unanticipated answers (Robson, 2002). All interviewees agreed to the interviews being recorded. The recordings 
were transcribed and the interviewees had the opportunity to comment on the transcripts and confirm their validity.

Due to the sensitive nature of the issues, two-way communication between the interviewer and the interviewees was required. The interviews were held over the telephone and lasted between 30 and 75 minutes each. Telephone interviews result in information losses due to lack of visual cues, but this may be counterbalanced by the smaller interviewer effect and lower tendency for socially desirable responses (Bradburn and Sudman, 1979).

The results of the interviews as well as the information presented in Section 2 are subject to a theoretical interpretation in Section 5, with occasional direct quotes from the interviews to support a particular point. For reasons of confidentiality, the interviewees are only numbered.

The six interviewees (here presented in random order) were or had been: a director of Swedish Meats; a chairperson in Swedish Meats' supervisory board; a chairperson of Swedish Meats; a director of Swedish Meats; a chairperson of a farmers' society in the meat industry; and an elected representative at the second highest hierarchical level of the cooperative society.

\section{Analysis}

\subsection{The national agricultural policy}

During most of the era of Swedish agricultural policy the politicised co-operative model was a "convention" (Aoki, 2007, p. 13) embraced by citizens, consumers, farmers, farmers' organisations and politicians of all colours. There was largely consensus that agriculture needed government support. The hierarchical order, with the farmers' federation at the top and farmers at the bottom, created a corporatist-like structure in Swedish agriculture.

There were shared beliefs and common knowledge about a specific co-operative ideology, e.g. that there should be solidarity between farmers (Nilsson, 1997); that suppliers in even the most remote districts should have the transport costs covered by the co-operative; and that ownership of the co-operative should be collective (Fahlbeck, 2007). This institution was more or less in equilibrium, with the exception of the few farmers who delivered to IOFs despite the disapproval of others.

The successful lobbying by the farmers' organisations for support for agriculture was the result of a "linked game" (Aoki, 2007, p. 15). The farmers' representatives obtained political support within the political domain, legitimacy and trust from farmer-members in the social exchange game, acceptance from suppliers, other businesses and consumers in the economic exchange domain, etc. Through this game, the institution of politically supported cooperatives was corroborated.

Aoki (2007, p. 17) explains the linkages between domains in terms of "institutional complementarities". Thus the representatives of the farmers' organisations treated the institutions within one domain as a parameter within another domain. These representatives were highly respected in the farming community, but had also good political connections. Co-operatives gained acceptance through the arguments that traditional co-operative business firms act to the benefit of society and that co-operatives constitute social movements. 
In the mid-1980s a diverging position was taken by some academics, who asserted that the institutional structure within the agricultural sector was inherently inefficient. This tension was uncovered by some journalists who saw personal advantages in allying themselves with the researchers. During subsequent mass media activities the general public gained the impression of farmers as social welfare claimants, paid with tax-payers' money. The result was that in 1990, the Swedish Parliament decided to dismantle the national agricultural policy and allow Swedish agriculture to operate under world market conditions.

During the debate about the liberalisation of Swedish agriculture the leaders of farmers' organisations expressed support for the new political conditions, even though they had fought for continuing support for agriculture a few years earlier. These farmers' representatives realised that it would be impossible to change the opinion of the public, politicians, the mass media, etc. Furthermore the co-operatives were so large, wealthy and market-dominating that it was difficult to conceive of a future in which they could be threatened. There may have been some "hubris and overconfidence" (cf. Fulton and Larson, 2009, p. 2). The leaders also enjoyed so much respect among the membership that they did not have to fear much opposition. The information asymmetry was large; farmers had learned to trust their representatives, so "normative conformity" existed (Dequech, 2013).

There was a mentality of grandiosity in the entire organisation, which felt as if it belonged to the politically regulated era. (Interviewee 4 )

However the farmers' leaders, just like farmers in general, had no experience of farming without government support and they hoped that such support would continue, although in some other way. One argument was that Sweden would probably soon join the EU with its CAP, which would provide a shield. This assertion was obviously not correct but it came to constitute a common belief in the farming community. Arguments made by the leaders of the farmers' organisations were not questioned.

In spite of the parliamentary deregulation decision and the support expressed by farmers' representatives for this decision, the previous political mentality within the agricultural sector persisted. The hierarchical order within the farmers' organisations prevented the elected representatives from stating deviating opinions. Most representatives wanted to be re-elected to their prestigious positions. There were social sanctions that prevented new ideas and solutions (Dequech, 2013). "The hindering factors are conservatism among members and difficult institutional conditions with regard to legislation and public opinion." (Nilsson, 1997, p. 62).

\section{My reflection is that we lacked competencies. (Interviewee 5)}

Hence the abolition of Swedish agricultural policy did not lead to major endogenous processes in the minds of farmers and their co-operative representatives. This absence of adaptation was due not least to the fact that further government deregulation measures were largely postponed owing to the expected entry into the EU.

\subsection{Sweden's accession to the EU}


Swedish meat producers were not prepared for the influx of imported goods following EU accession and the meat co-operatives did not undertake any major strategic changes. In accordance with the culture within the co-operatives, the decision-makers convinced each other and farmers that in the long run, consumers would remain loyal to products of Swedish origin.

The Swedish meat industry, the farmer co-operatives, were very badly prepared for the EU accession and never kept up, regrettably. ... The imports surprised those who were responsible for the slaughtering at the time of the EU accession. (Interviewee 3)

In the 1990s the co-operatives no longer had any influence in the political exchange domain. After foreign products became increasingly popular among consumers, the co-operatives had difficulties in parts of the social exchange domain because their legitimacy in relation to consumers and the general public was vanishing. The co-operatives' role in part of the economic exchange domain was also challenged as regards relations to retailers and consumers. Hence, the main arena that remained for the farmers' representatives was the social exchange domain, limited to farmer-members.

For the co-operative leaders, it was important to maintain good relations with the farmermembers. Hence, the co-operatives sought to retain the support of members by paying a higher price for animals than they could afford (Interviewee 1). The co-operatives thereby drained their accumulated savings, but their leaders had still faith in the strength of the cooperative model.

The Board of Directors was incompetent in relation to their task ... they lacked knowledge and courage. It is difficult to communicate to the members that we'll have to lower the prices in order to make it. ... There was too much politics ... They discussed everything except the things that were really important for the ability to pay for the animals. (Interviewee 5)

In relation to the farmers, the co-operatives tried to maintain a balance between the social and economic domains. The members were told that the co-operatives' operations were under control. The farmers' product prices were unaffected and in any case the farmers could not access the capital in the collective funds, which covered the losses. A challenge to the cooperative leaders' belief was that some farmers' trust in the co-operatives deteriorated and an increasing number of members began delivering their animals to competing investor-owned slaughterhouses.

It was felt that the Board to some part was quite paralysed and did not have any visions and ideas and initiative to survive this. (Interviewee 4)

\subsection{The meat co-operatives}

The attempt to solve the co-operatives' problems by amalgamating the four regional cooperatives resulted in 1999 in a loose coalition, but in 2001 the almost nation-wide Swedish Meats was established. However, this merger was based on political considerations rather than economic reality.

Swedish Meats was thoroughly politicised. (Interviewee 5) 
The merging partners were quite unequal in terms of financial strength, operational attributes and co-operative policies (Nilsson, 1997; Svensson, 1997). The cultural and economic differences not only postponed the merger for two years, but continued to create conflicts between the representatives, especially the merging partner with many large pig producers and that with many suppliers of dairy cattle. The new co-operative also comprised both Southern Sweden (with intensive agriculture) and the North (with few and dispersed farms). The result was that the membership was very heterogeneous (Interviewee 6). The members' interests were thus difficult to align and the possibilities to run efficient operations were circumscribed. The disputes partly paralysed decisions about efficiency raising measures.

The merger was intended to cut costs but no measures were considered. (Interviewee 1)

The directors of the two major merging partners could not reach agreement about who should have the leading positions. There were two separate endogenous processes, linked to these two former co-operatives. The disputes could be understood in light of the tradition of hierarchical organisational structures in the co-operative sector (Interviewee 4). The chairpersons had the power to support farmer-members and representatives in their own region. Each tried to use their network within staff and members. In reality, neither of the two wings represented the entire membership. The conflict was partly a result of different conceptions of co-operative business principles.

There was a political power game among the elected representatives of gigantic proportions. (Interviewee 4)

The conflicts within the Board of Directors meant that Swedish Meats did not undertake sufficient measures to reduce its cost level. For example, even though the number of subsidiary companies was reduced, the Board of Directors chose to let the top managers remained employed, in other high-salaried positions (Interviewee 5).

So there are these "popes" [former Chief Executive Officers] who remained after the merger and each of them ... refused to loosen their grip and would not leave their position.

(Interviewee 1)

The members were aware of the conflicts between their leaders (Interviewee 1). Their confidence in the co-operative declined as the mass media reported how these conflicts hampered efficiency measures.

It was about leadership ... If the co-operative had had the right chairman ... this person would have been able to make some tough decisions and pedagogically explain them ... A person with strong leadership skills could have compensated for the heterogeneous membership ... (Interviewee 5)

As Swedish Meats made losses, its reputation became increasingly poor within the membership. Thus more and more members chose a free-rider policy, selling their animals to IOF slaughterhouses. They realised that the co-operative's business operations were untenable. It was easy for members to defect, but more difficult for them to fight for the cooperative to become successful (Interviewee 1). 
The members wanted better prices for their animals and they got that or, putting it differently, they got a better payment than the co-operative could afford and the result was this. At the same time as they wanted better payment, they didn't want to restructure the [co-operative] organisation. They wanted to have, but not to give. (Interviewee 5)

Within a subgroup of farmers a mentality evolved; any farmer wishing to be regarded as modern, successful and good at business had to leave Swedish Meats and deliver to an IOF. As this opinion became more widespread, the number of exiting suppliers increased (Lind and Åkesson, 2005). These farmers were predominately large producers, so Swedish Meats also lost much equity capital. The remaining member-suppliers thus bore an increasingly heavy burden. Hence smaller farmers also had an incentive to leave 'the sinking ship'. This 'bank run' continued for some time and many members exited. According to Dequech (2013), the sequential development of positive norms in relation to IOF slaughterhouses was due to "coordination and increasing returns to adoption".

People already had zero confidence in Swedish Meats and that could not be repaired. (Interviewee 6)

As Swedish Meats' financial crisis worsened, the controversies between the two stronger merging partners faded away. Ultimately, some directors left their positions a few years before Swedish Meats finally collapsed. Many new directors were elected, but by then Swedish Meats' reputation among farmers was beyond repair.

The primary task of the new directors was to find an alternative organisational solution (Interviewee 1). Because a statement on selling Swedish Meats would have been quite bold, the Board started by leaking to the media that Swedish Meats wanted to form an alliance with a stronger firm (Interviewee 3). It was later announced that Swedish Meats had to sell its operations. When the General Assembly voted to sell the co-operative, the conflict between the small number of pig breeders and the larger number of dairy producers was evident.

\section{Mainly the pig farmers said "no" and especially those from the production intensive regions. The [merger] decision was actually forced through by the weaker regions with dairy cattle. (Interviewee 4)}

In summary, Swedish Meats' failing adaptation to new market conditions related to its organisational attributes. It was by far the largest firm in the industry, so the decision-makers considered it to have all necessary expertise inside the organisation and were unreceptive to signals from outside. For an extended period it was possible to keep the support of the farmer-members. The size and wealth of the organisation meant that there were good career opportunities for farmers to become elected representatives at increasingly high levels of the organisational hierarchy. Members had good reason to be compliant and normative conformity could be achieved.

The co-operative's heritage from the governmental agricultural policy explains the hierarchical organisational structure both in the business firm and in the co-operative society. These organisational attributes hampered endogenous learning processes. The organisation did not consider itself to have much to learn from outside.

\section{Conclusions}


The institutional changes within the Swedish meat industry during recent decades, following abolition of the national agricultural policy in 1990 and Sweden's accession to the European Union in 1995, were analysed here using institutional change theory. In an attempt to manage the new market conditions, four out of five meat co-operatives merged in 2001 but this nation-wide co-operative had to be sold in 2007. The meat industry at large declined because the market-dominating meat co-operative collapsed.

Institutional changes took place successively, with each actor's beliefs, conceptions, expectations and other cognitive states influenced by those of other actors in a large interactive system. Swedish researchers inspired the mass media, which affected public opinion, resulting in Parliament abolishing Swedish agricultural policy. The farmers' leaders were forced to support this political decision and use their authority to convince farmers that Swedish agriculture would survive. Similarly, they succeeded in reassuring farmers when Sweden joined the European Union and cheap imported food posed a threat to Swedish producers.

The co-operative members at large remained as suppliers for an extended time, even though the co-operatives performed poorly. One explanation is that the members had the same cooperative culture as the elected representatives and the business organisation. This is likely, because the co-operative repeatedly informed them about the merits of the existing cooperative structure and there were marked informational differences between the members and the leaders. However, after the small, weak IOF slaughterhouses reorganised so that they could pay higher prices for farmers' animals, it became evident that many farmers had no cooperative loyalty. Those who exited worsened conditions for remaining members and farmers with large production enterprises were more prone to exit. A new culture evolved among farmers, praising IOFs and criticising co-operatives.

The meat co-operatives' orientation towards the old political market hindered their adaptation to new commercial market conditions, where they had to compete with cheap imported food products. In accordance with the political mentality there were internal power struggles, which delayed reforms.

All the actors involved in the development acted in a way that was consistent with the set of norms that existed in their social context at the time when they were in charge of decision making. Nobody can be blamed for the development. Those involved can rather be seen as victims of the past, in this study tracked back to the former agricultural policy.

This case shows that ideologies can survive in an organisation despite external influences. Both the management and the Board of Directors adhered to the conceptions of co-operative management that dominated during the years of Swedish agricultural policy. Seen from the leaders' perspective, this strategy was rational. By adhering to the old ideology the individuals retained their power for several years. This came to an end eventually, however, as the leaders had no power over other actors within the value chain, including the farmermembers.

Situations similar to that described here may occur in other organisations which have a glorious history. There are other collectively governed and hierarchically structured organisations with power concentrated at the top. These attributes hamper external influences 
and therefore endogenous thought processes get less stimulation. Such organisations may have a strong ideology that serves to isolate them from the outside world. These ideologies may be political, religious, or - as in the present case - a conviction about the benefits of politically governed co-operatives.

\section{References}

Andersson, H. and Thorstensson, F. (2010), Swedish Meats - motiven bakom försäljningen av kooperationen (Swedish Meats - the motives behind the sale of the cooperative). Master's thesis 628. Department of Economics, Swedish University of Agricultural Sciences, Uppsala, Sweden. (In Swedish)

Aoki. M. (2007), "Endogenizing institutions and institutional changes", Journal of Institutional Economics, Vol. 3 No 1, pp. 1-31.

Aoki, M. (2011), "Institutions as cognitive media between strategic interaction and individual beliefs", Journal of Economic Behavior and Organization, Vol. 79 No 1, pp. 20-34.

Bager, T. (1996), Organisations in Sectors. Explaining the Dissemination of Populations of Formal Organization in Economic Sectors - Bridging Rational Choice and Institutional Approaches, South Jutland University Press, Esbjerg, Denmark.

Bradburn, N.M. and Sudman, S. (1979), Improving Interview Method and Questionnaire Design, Jossey-Bass, San Francisco, CA.

Cook, M.L. (1995), "The future of U.S. agricultural cooperatives: A neo-institutional approach". American Journal of Agricultural Economics, Vol. 77 No. 5, pp. 1153-1159.

Dequech, D. (2013), "Economic institutions: explanations for conformity and room for deviation", Journal of Institutional Economics, Vol. 9 No. 1, pp. 81-108,

Fahlbeck, E. (2007), “The horizon problem in agricultural cooperatives - Only in theory?" In Karantininis K. and Nilsson J. (Eds), Vertical Markets and Cooperative Hierarchies, Springer, Dordrecht, pp. 255-274.

Fulton, M.E. and Larson, K. (2009), "The restructuring of the Saskatchewan Wheat Pool: Overconfidence and agency". Journal of Cooperatives, Vol. 23, pp. 1-19.

Hakelius K., Karantininis K. and Feng L. (2013), "The resilience of the cooperative form: cooperative beehiving by Swedish cooperatives", Ehrmann, T., Windsperger, J., Cliquet, G., Hendrikse, G. (Eds.), Network Governance, Contributions to Management Science. Springer, Berlin Heidelberg, pp. 127-147.

Harte, L.N. (1997), "Creeping privatisation of Irish co-operatives. A transaction cost explanation". In J. Nilsson and G. Van Dijk (Ed.) Strategies and Structures in the Agro-food Industries (pp. 31-53), Van Gorcum, Assen, Netherlands.

Hess, S., Lind, L.W. and Liang, S. (2013), "Farmers' perceived transaction costs in relation to slaughterhouses of different ownership structure", Agribusiness, Vol. 29 No. 1, pp. 96111.

Hind, A.M. (1999), "Co-operative life cycle and goals". Journal of Agricultural Economics, Vol. 50 No. 3, pp. 536-548.

Hogeland, J.A. (2006), "The economic culture of U.S. agricultural cooperatives". Culture and Agriculture, Vol. 28 No 2, pp. 67-79.

Ilmonen, K. (1992), The End of Cooperative Movement, Labour Institute of Economic Research, Helsinki, Finland.

King, N. (1994), "The qualitative research interview", Cassell C. and Symon G. (Eds.), Qualitative Methods in Organisational Research: A practical guide, 14-36. Sage, London, UK. 
Lind, L.W. (2011), Market Orientation in the Swedish Pork Sector. The Case of the Demutualization of Swedish Meats, Swedish University of Agricultural Sciences, Uppsala, Sweden.

Lind, L.W. and Åkesson, E. (2005), "Pig producers' choice of slaughterhouse - co-operative or investor-owned?" International Journal of Co-operative Management, Vol. 2 No. 2, pp. $40-46$.

Micheletti, M. (1987), “Organization and representation of farmers' interest in Sweden", Sociologia Ruralis, Vol. 27 No. 2-3, pp. 166-180.

Nilsson, J and G.T. Svendsen (2011). "Free riding or trust? Why members (do not) monitor their co-operatives". Journal of Rural Cooperation, Vol. 39 No. 2, pp. 131-150. .

Nilsson, J. (1997), “Inertia in Cooperative Remodeling”, Journal of Cooperatives, Vol. 12, pp. 62-73.

Nilsson, J. and Björklund, T. (2003), Kan kooperationen klara konkurrensen? (Can cooperatives cope with the competition?), Report 149, Department of Economics, Swedish University of Agricultural Sciences, Uppsala, Sweden. (In Swedish)

Nilsson, J., Kihlén, A. and Norell, L. (2009), "Are traditional cooperatives an endangered species? About shrinking satisfaction, involvement and trust". International Food and Agribusiness Management Review, Vol. 12 No. 4, pp. 103-123.

Nilsson, J., Svendsen, G.L.H., and Svendsen G.T. (2012), ”Are large and complex agricultural cooperatives losing their social capital?" Agribusiness, Vol. 28 No. 2, pp. 187-204.

North, D. (1990), Institutions, Institutional Change and Economic Performance, Cambridge, UK and New York: Cambridge University Press.

Pestoff, V. (1991), Between Markets and Politics. Cooperatives in Sweden, Campus/Westview, Frankfurt/Boulder CO.

Rabinowicz, E. (2004), “The Swedish agricultural policy reform of 1990 - A window of opportunity for structural change in policy preferences". Paper presented to International Agricultural Trade Research Consortium "Adjusting to Domestic and International Agricultural Policy Reform in Industrial Countries", Philadelphia, PA, June 6-7. Available at: http://ageconsearch.umn.edu/bitstream/15760/1/cp04ra01.pdf (accessed 18 November 2014)

Rabinowicz, E., Haraldsson, I. and Bolin, O. (1986), "The evolution of a regulation system in agriculture: The Swedish Case”, Food Policy, Vol. 17 No. 4, pp. 323-333.

Robson, C. (2002), Real world research: a resource for social scientists and practitionersresearchers. Second edition, Blackwell Publishing, Oxford, UK.

Svensson, R. (1997), Exportfinansiering i animaliebranscherna (Export Financing in the Swedish Meat, Egg and Dairy Industries). Report 115. Uppsala, Sweden: Department of Economics, Swedish University of Agricultural Sciences. (In Swedish)

Swedish Board of Agriculture (2013), Rapport 2013:2, SJV, Jönköping, available at: http://www.jordbruksverket.se/webdav/files/SJV/Amnesomraden/Statistik\%2C\%20fakta/H usdjur/JO20/JO20SM1401/JO20SM1401_ikortadrag.htm

Swedish Board of Agriculture (2014), publication JO 20 SM 1401, SJV, Jönköping, available at:

http://www.jordbruksverket.se/download/18.39da9f0113cb389bda880001123/Ra+2013_2. pdf (accessed 18 November 2014).

Swedish Meats. (1999-2007), Annual Reports, 1999-2007. Swedish Meats, Stockholm, Sweden. 